\title{
Eukaryotic signaling pathways targeted by Salmonella effector protein AvrA in intestinal infection in vivo
}

\author{
Xingyin Liu', Rong Lu', Yinglin Xia², Shaoping $\mathrm{Wu}^{1}$, Jun Sun ${ }^{1,3,4^{*}}$
}

\begin{abstract}
Background: The Salmonella AvrA gene is present in $80 \%$ of Salmonella enterica serovar strains. AvrA protein mimics the activities of some eukaryotic proteins and uses these activities to the pathogen's advantage by debilitating the target cells, such as intestinal epithelial cells. Therefore, it is important to understand how AvrA works in targeting eukaryotic signaling pathways in intestinal infection in vivo. In this study, we hypothesized that AvrA interacts with multiple stress pathways in eukaryotic cells to manipulate the host defense system. A whole genome approach combined with bioinformatics assays was used to investigate the in vivo genetic responses of the mouse colon to Salmonella with or without AvrA protein expression in the early stage (8 hours) and late stage (4 days). Specifically, we examined the gene expression profiles in mouse colon as it responded to pathogenic Salmonella stain SL1344 (with AvrA expression) or SB1117 (without AvrA expression).
\end{abstract}

Results: We identified the eukaryotic targets of AvrA and the cell signaling pathways regulated by AvrA in vivo. We found that pathways, such as mTOR, NF-kappaB, platelet-derived growth factors, vascular endothelial growth factor, oxidative phosphorylation, and mitogen-activated protein kinase signaling are specifically regulated by AvrA in vivo and are associated with inflammation, anti-apoptosis, and proliferation. At the early stage of Salmonella infection, AvrA mainly targeted pathways related to nuclear receptor signaling and oxidative phosphorylation. At the late stage of Salmonella infection, AvrA is associated with interferon-gamma responses.

Conclusion: Both early and late phases of the host response exhibit remarkable specificity for the AvrA+ Salmonella. Our studies provide new insights into the eukaryotic molecular cascade that combats Salmonellaassociated intestinal infection in vivo.

\section{Background}

The capacity of pathogenic Salmonella to infect their hosts is often dependent on the ability of Salmonella to inject virulent factors directly into the host cell cytosol through the type-three secretion system (TTSS). These injected bacterial proteins, called effectors, are of special interest in studies of host-pathogen interactions because effectors can manipulate host cell function $[1,2]$. The effectors often have unique functions suited to a particular pathogen's infection strategy.

AvrA is a Salmonella effector that is translocated into host cells [3]. The AvrA gene is present in $80 \%$ of

\footnotetext{
* Correspondence: jun_sun@urmc.rochester.edu

'Department of Medicine, Gastroenterology \& Hepatology Division,

University of Rochester, 601 Elmwood Avenue, Rochester, NY 14642, USA

Full list of author information is available at the end of the article
}

Salmonella enterica serovar Typhimurium strains [4]. Previous studies show that AvrA related family members include Yersinia virulence factor, YopJ, and the Xanthomonas campestris pv.vesicatoria protein, AvrBsT [5]. Analysis with MEROPS database shows that AvrA belongs to YopJ-like proteins and genes (family C55) in bacterial species (see details in http://merops.sanger.ac. uk). Many studies highlight the remarkable complexity of the TTSS system and AvrA's function. Studies show that AvrA possesses enzyme activities to remove the ubiquitins from $\mathrm{I} \kappa \mathrm{B} \alpha$ and $\beta$-catenin, to transfer acetyl to inhibit JNK activity and to bind with Erk2 and MKK7 [6-9]. Although AvrA is known to regulate diverse bacterial-host interactions, the eukaryotic targets of AvrA are still not completely identified.
C Biomed Central

(c) 2010 Liu et al; licensee BioMed Central Ltd. This is an Open Access article distributed under the terms of the Creative Commons Attribution License (http://creativecommons.org/licenses/by/2.0), which permits unrestricted use, distribution, and reproduction in any medium, provided the original work is properly cited. 
Gene expression array technology is a powerful tool that has been used to expand the understanding of host-pathogen interactions. A number of reports have described host transcriptional responses to bacterial infection using microarrays [9-14], but the global physiological function of Salmonella effector protein AvrA in vivo is unclear. A whole genome approach, combined with bioinformatics assays, is needed to elucidate the in vivo genetic responses of the mouse colon to Salmonella, and particularly to effector protein AvrA.

In this study, we hypothesized that AvrA interacts with multiple pathways in eukaryotic cells to manipulate the host defense system. A central feature of $S$. Typhimurium pathogenesis is its ability to induce intestinal inflammation [9]. Hence, we specifically examined the gene expression profiles in mouse colon when it responded to pathogenic Salmonella stain SL1344 (with AvrA expression) or SB1117 (without AvrA expression). SB1117 is an AvrA mutant strain derived from SL1344. We focused on the intestinal responses to Salmonella infection at the early phase ( 8 hours) and the late phase (4 days). Ingenuity Pathways Analysis (IPA) was used to search for networks of biologically related genes that were co-regulated or differentially regulated in response to SL1344(AvrA+) and SB1117 (AvrA-). The gene expression differences found with the microarray were confirmed using real-time quantitative reverse transcription PCR (qRT-PCR). We identified the eukaryotic cell targets of AvrA and confirmed the eukaryotic cell signaling pathways targeted by bacterial effector protein AvrA. These studies underscore the importance of the Salmonella effector AvrA in intestinal-bacterial interactions.

\section{Methods}

\section{Bacterial strains and growth conditions}

Salmonella typhimurium wild-type strain SL1344 (WT) and Salmonella AvrA mutant strain SB1117 derived from SL1344 (provided by Dr. Galan) [3,9]. Non-agitated microaerophilic bacterial cultures were prepared by inoculating $10 \mathrm{ml}$ of Luria-Bertani broth with $0.01 \mathrm{ml}$ of a stationary phase culture, followed by overnight incubation $(\sim 18 \mathrm{~h})$ at $37^{\circ} \mathrm{C}$ as previously described $[15,16]$.

\section{Streptomycin pre-treated mouse model}

Animal experiments were performed using specificpathogen-free female C57BL/6 mice (Taconic, Hudson, NY) that were 6-7 weeks old. The protocol was approved by the University of Rochester University Committee on Animal Resources (UCAR). Water and food were withdrawn 4 hours before oral gavage with $7.5 \mathrm{mg} /$ mouse of streptomycin. Afterwards, animals were supplied with water and food ad libitum. Twenty hours after streptomycin treatment, water and food were withdrawn again for 4 hours before the mice were infected with $1 \times 10^{7}$ CFU of S. Typhimurium (100 $\mu \mathrm{l}$ suspension in HBSS) or treated with sterile HBSS (control) by oral gavage as previously described [17]. The wild-type Salmonella and AvrA mutant strains were in the same phase of growth. Mice without Salmonella infection were set up as the control group $(\mathrm{n}=3)$. At 8 hours and 4 days after infection, mice were sacrificed and tissue samples from the intestinal tracts were removed for analysis, as previously described $[17,18]$. Three independent biological replicates in every group were performed.

\section{Sample RNA preparation}

Mice were sacrificed at 8 hours and 4 days after Salmonella infection, and tissue samples from the intestinal colon mucosa were removed. Total RNAs were isolated using TRIzol reagent (Invitrogen) following the manufacturer's protocol, followed by on-column digestion of DNA using the RNeasy Mini Kit (Qiagen). RNA quantity and quality were assessed with a Beckman Coulter DU 640 Spectrophotometer (Beckman Coulter) and Agilent 2100 Bioanalyzer (Agilent), following the manufacturer's protocols.

\section{Gene array processing and statistical analysis}

The biotinylated single-stranded cDNA was prepared from $100 \mathrm{ng}$ total intact RNA extracted from Salmonella infected mouse mucous at 8 hours and 4 days postinfection, or from uninfected mouse control samples. Mouse cDNA was hybridized to the Mouse Gene 1.0 ST array, a microarray chip containing 28,000 sequenced mouse genes (Affymetrix, Santa Clara, CA).

After hybridization, the array was washed and stained with streptavidin-phycoerythrin, and scanned in a proprietary Affymetrix scanner, according to the GeneChip ${ }^{\circledR}$ Whole Transcript Sense Target Labeling Assay manual. The fluorescence values for each feature on the array were measured and recorded. Suite Software (Affymetrix) was used to produce a CEL file. The data were processed with Expression Console (Affymetrix) using the PLIER algorithm. The Array Assist Lite software package was used to generate GC-RMA files ( $\log 2$ transformed) for each chip. All procedures were performed in triplicate at the Functional Genome Center of the University of Rochester. Fold change was calculated for each strain relative to the uninfected control. Statistical significance ( $p$ value) was calculated by Student's $t$ test, based on the results of three separate experiments. Insignificant genes that changed by less than 1.2 fold were removed from subsequent analysis. The 1.2 cut-off is acceptable in the genomics analysis field $[19,20]$. 


\section{Gene ontology enrichment and pathway analysis}

Degree of enrichment for cellular component, biological processes and molecular functions was assessed by the Gene ontology (GO) program [21].

IPA (Ingenuity Systems http://www.ingenuity.com) is a web-based software application tool, which allows for the mapping of gene expression data into relevant pathways based on their functional annotation and known molecular interactions [22-24]. Differential expression analyses between the normal control and Salmonellainfected groups were carried out with GeneSifter software.

The IPA program was used mainly for signal transduction pathway analyses and generating pathway figures and tables of related candidate genes. To compare the significant value of the canonical pathway associated with SL1344 and SB1117 infection, we used the Canonical Pathway analysis software package in IPA software. The significance of a given pathway in a dataset is a measurement of the likelihood whether this pathway is associated with the dataset by random chance. IPA software can compare one observation to another. Within a comparison, we could start by comparing the extent to which the significances change from one observation to another. Significance of the canonical pathways was tested by the Fisher Exact test. Data from repeated experiments were clustered within 1.2-fold changes, indicating that the experiments produced reproducible data.

\section{Hierarchical Cluster analysis}

After removing duplicate probe sets, a total of 904 genes showed $p$-value $\leq 0.05$ and estimated $\mathrm{FC} \geq 1.2$ at least one of the 4 group samples pair-wise comparisons during SL1314 and SB1117 infection respectively (SL1344 at 8 hours vs. Control, SL1344 at 4 days vs. Control, SB1117 at 8 hours vs. Control and SB1117 at 4 days vs. Control). This list was used to perform a hierarchical cluster analysis and to construct a heat map using the Gene Cluster 3.0 and tree view software (Stanford University, 2002).

\section{Real-time quantitative reverse transcriptase PCR (qRT- PCR)}

Total RNA was reverse transcribed with oligoDT primer using an Invitrogen SuperScript III kit. The cDNA was subject to qRT-PCR using SYBR Green Supermix (BioRad). A total of 10 differentially-expressed genes in microarray data were chosen for further analysis. Primers of target genes are listed in Additional file 1 Table S1. The amplification conditions were optimized for the MJ research DNA Engine instrument, using melting curve and electrophoresis analysis. The cycling conditions using SYBR green detection were $95^{\circ} \mathrm{C}$ for $2 \mathrm{~min}$, followed by 40 repetitive cycles at $95^{\circ} \mathrm{C}$ for $15 \mathrm{~s}$, $58-60^{\circ} \mathrm{C}$ for $40 \mathrm{~s}$, and $72^{\circ} \mathrm{C}$ for $30 \mathrm{~s}$. A melting curve analysis was performed from $60^{\circ} \mathrm{C}$ to $95^{\circ} \mathrm{C}$. $\beta$-actin was selected as the endogenous control. The threshold cycle $(\mathrm{Ct})$ was determined, i.e. the cycle number at which the fluorescence of the amplified product crosses a specific threshold value in the exponential phase of amplification. Relative quantification of target gene expression was evaluated using the comparative cycle threshold method as previously described by Livak and Schmittgen [25].

\section{Results and Discussion}

\section{Gene expression in the mouse colon in response to Salmonella infection}

In this study, we focused on in vivo intestinal responses to Salmonella AvrA using the SL1344 (AvrA+) and AvrA- strain SB1117. SL1344 is known to constitutively express AvrA protein [3,26,27]. SB1117 lacks AvrA protein expression due to the AvrA mutation derived from SL1344 $[3,18,26]$. We performed microarray hybridization with RNA from mouse colon mucosa. Biotinlabeled target cDNAs prepared from total RNA extracted were hybridized to the microarray chip containing 28,000 sequenced genes. We selected genes that changed in response to Salmonella infection at 8 hours and 4 days time points. Clustering algorithm analysis indicated that the data generated in different arrays at the same time points were tightly clustered (data not shown).

\section{Cluster analysis}

In order to obtain a broad overview of the changes in gene expression during SL1344 and SB1117 infection and identify differentially expressed genes clusters between SL1344 infection and SB1117 infection, we generated a heat map using Gene cluster 3.0 for the 913 differentially expressed genes. As shown in Figure 1 overall, SL1344 infection and SB1117 infection showed similar gene expression cluster at 8 hours and 4 days. Four distinct clusters were produced: group A indicated a repressed gene cluster at 8 hours and 4 days; group B indicated an up-expressed gene cluster at 8 hours but a down-expressed cluster at 4 days; group $\mathrm{C}$ indicated a down-expressed gene cluster at 8 hours but an upexpressed cluster at 4 days; group D indicated an induced gene cluster at 8 hours and 4 days.

We further identified some subset groups (indicated with *), which suggested that SL1344 and SB1117 infection differentially regulated genes at both the early stage and the late stage. These results indicate that AvrA is involved in altering host responses in the Salmonellaintestine interaction in vivo. 


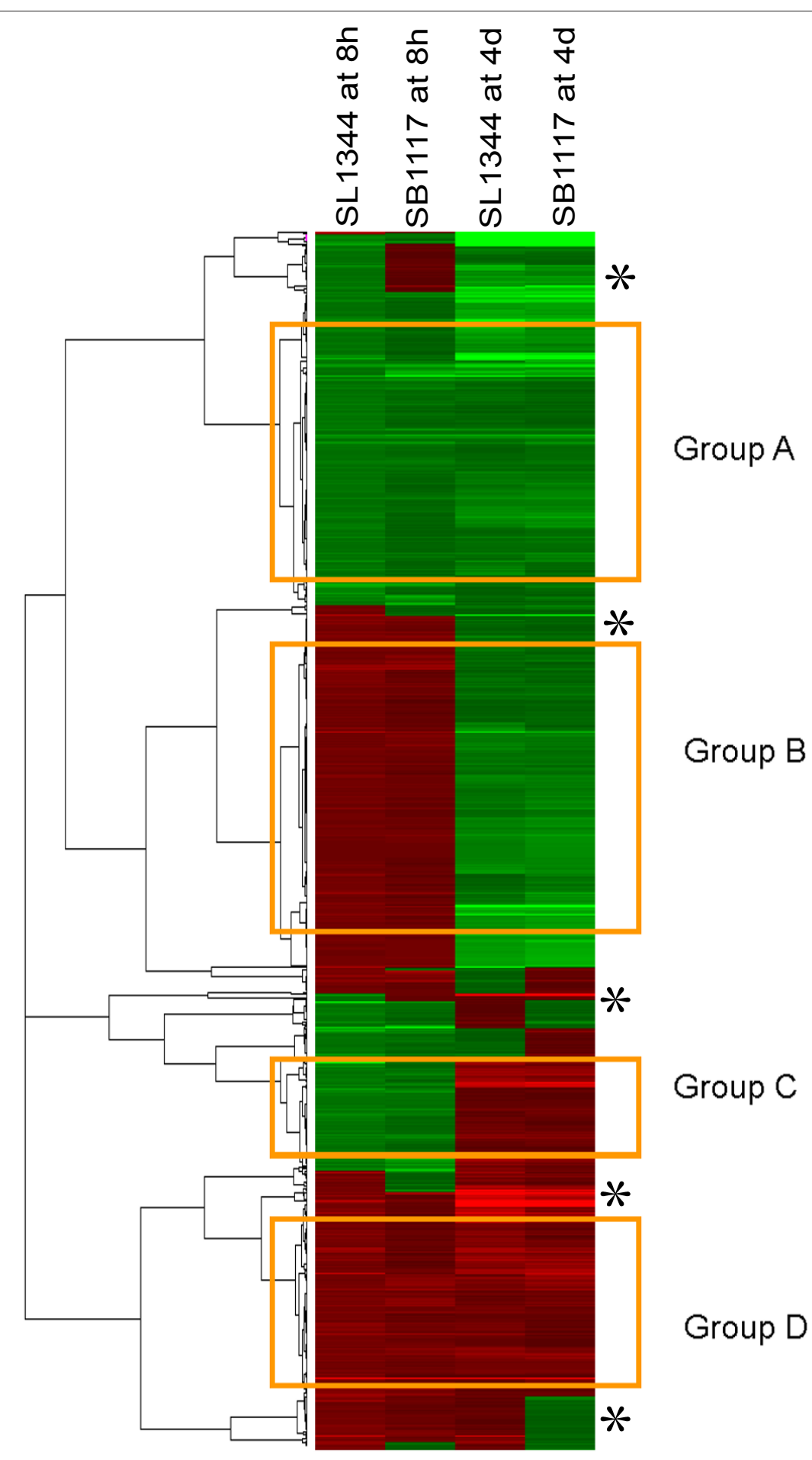

Figure 1 Hierarchical clustering analysis of 913 genes from Affymetrix array analysis showing differential expression patterns during SL1344 (WT AvrA) infection and SB1117(AvrA-) infection. A indicates repressed gene cluster at 8 hours and 4 days; B indicates a upexpressed gene cluster at 8 hours but a down-expressed cluster at 4 days; $C$ indicates a down-expressed gene cluster at 8 hours but a upexpressed cluster at 4 days; and D indicates an induced gene cluster at 8 hour and 4 days. Subset group was indicated with*. The heat map was built by using Gene Cluster 3.0 software. Red color represents up-regulation and green shows down-regulation. 
Characteristics of differentially expressed genes between the SL1344 and SB1117 infection groups

Our cluster analysis for the SL1344 (AvrA+) and SB1117 (AvrA-) infection groups have indicated that AvrA expression in the Salmonella strains clearly alters the in vivo host responses to intestinal infection. In order to get a broad overview of the mouse colon transcriptional changes induced by Salmonella Typhimurium SL1344 effector AvrA, fold change in gene expression was calculated for each SL1344 infection group relative to each SB1117 infection group (Figure 2).

In the SL1344 infection group, compared to the SB1117 infection group, at 8 hours post infection, 347 (58\%) genes were up-regulated and 227 genes (42\%) were down-regulated (Figure 2 and Additional file 2 Table S2, Fold times $\geq 1.2$ times, $\mathrm{P} \leq 0.05)$. In the SL1344 infection group at 4 days, 268 genes (44\%) in the group were up-regulated and 337 genes (56\%) were down-regulated, compared to the SB1117 infection group (Figure 2 and Additional file 3 Table S3, Fold times $\geq 1.2$ times, $\mathrm{P} \leq 0.05$ ). The majority of the genes that were differentially expressed between groups showed moderate alterations in expression of 1.2 to 2.0 folds (Additional file 2 Table S2 and Additional file 3 Table S3). Overall, the results indicate that AvrA protein by TTSS must be responsible for the induction and repression of in vivo transcriptional reprogramming of the host cells in intestinal infection (Figure 2).
To investigate co-regulated biological processes by AvrA during the early and late stages of SL1344 infection, we searched co-differentially expressed genes during the infection by using Filter datasets package of IPA software: DNAH3 was the only annotated up-regulated gene at both 8 hours and 4 days post infection; it is involved in nucleotide binding, ATP binding and microtubule motor activity. GRK5 (G protein-coupled receptor kinase 5) was the only annotated down-expressed gene at both 8 hours and 4 days post infection. GRK5 plays a positive role in Crohn's disease [28]. Salmonella infection increases the risk of inflammatory bowel diseases (IBD) including Crohn's disease [29]. It is interesting to explore the potential role of AvrA in the Salmonella-related IBD. Notch3 was annotated with up-regulation at 8 hours post infection, but showed down-expression at 4 days post infection. MS4A7 was down-expressed at 8 hours post infection and upexpressed at 4 days post infection. These unique co-regulated genes suggest that AvrA function is differentially regulated in host cells in association with infection time.

\section{Validation of microarray findings with real-time PCR}

To validate microarray results, we selected 10 differentially expressed genes between SL1344 infection group and SB1117 infection group for qRT-PCR. All of qRTPCR analyses were performed in samples previously used for the microarray experiments (Figure 3). Figure $3 \mathrm{~A}$ and Figure $3 \mathrm{~B}$ showed the fold times in gene

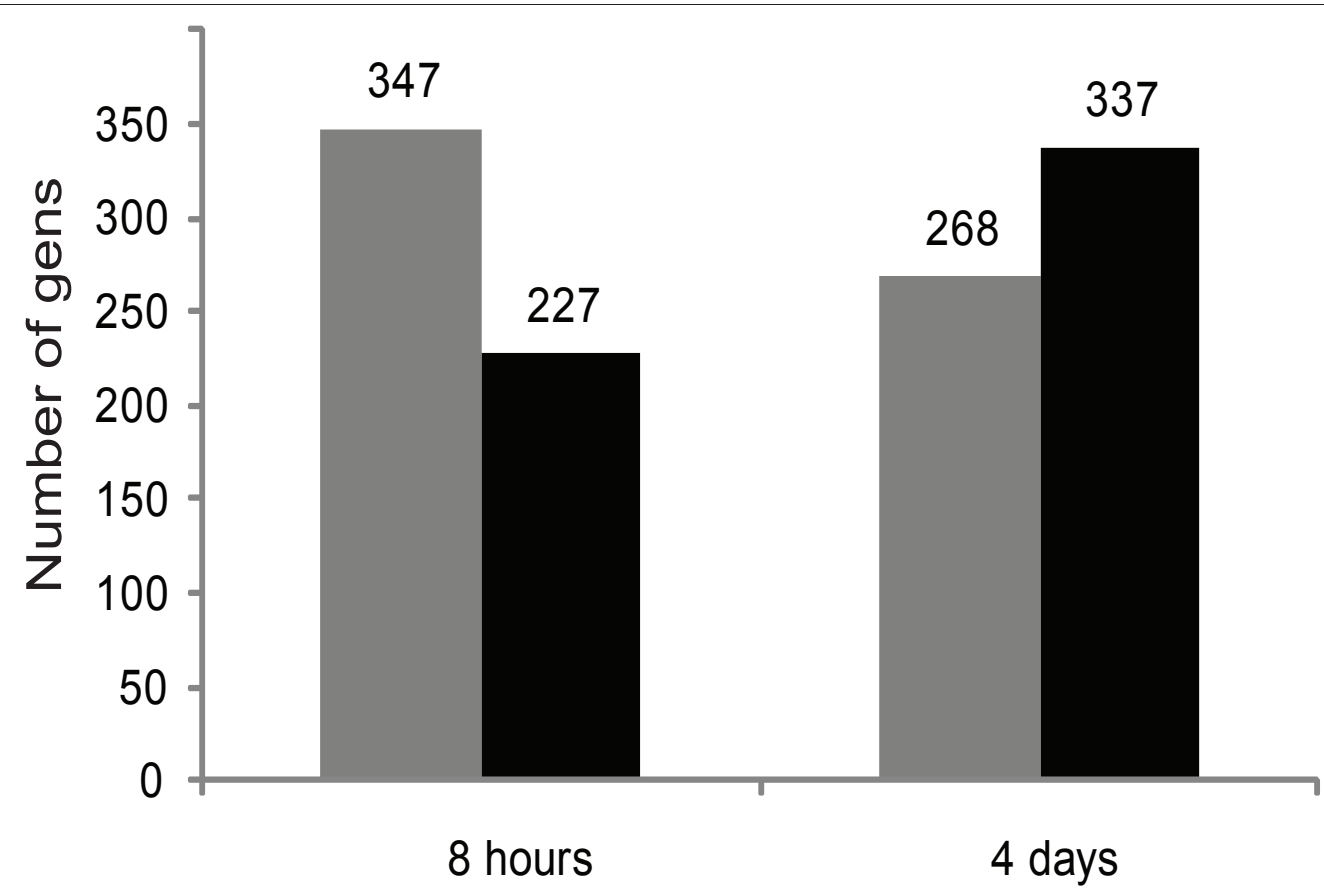

Figure 2 The number of differentially expressed genes between infection with salmonella, SL1344 (WT, AvrA) and SB1117(AvrA-). 


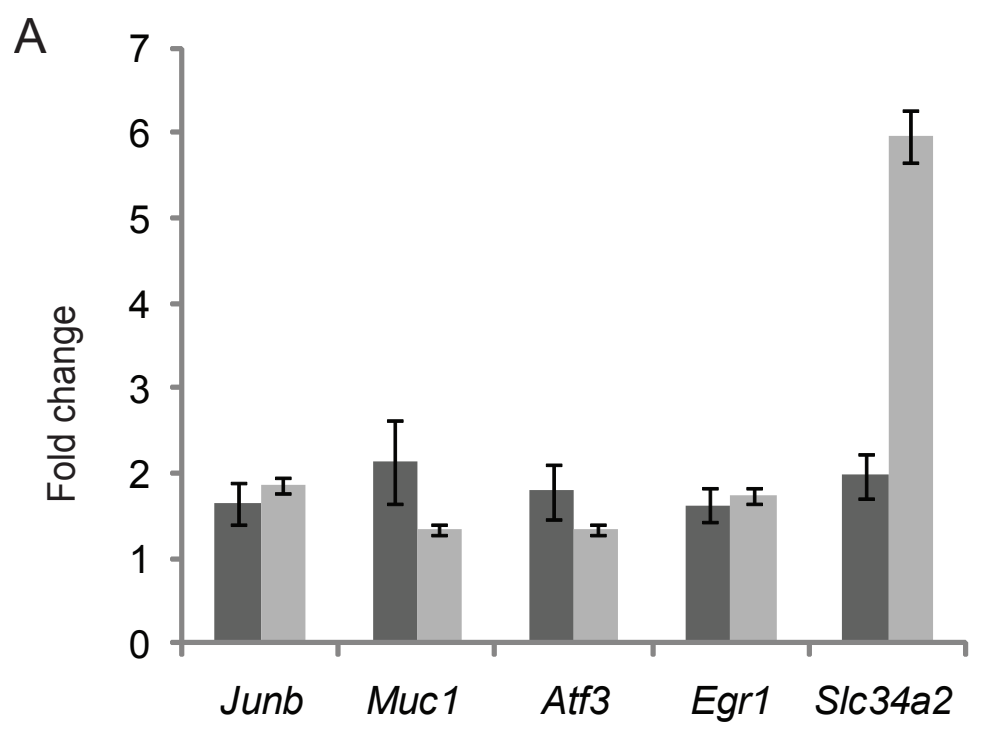

Microarray

Real-time PCR

B

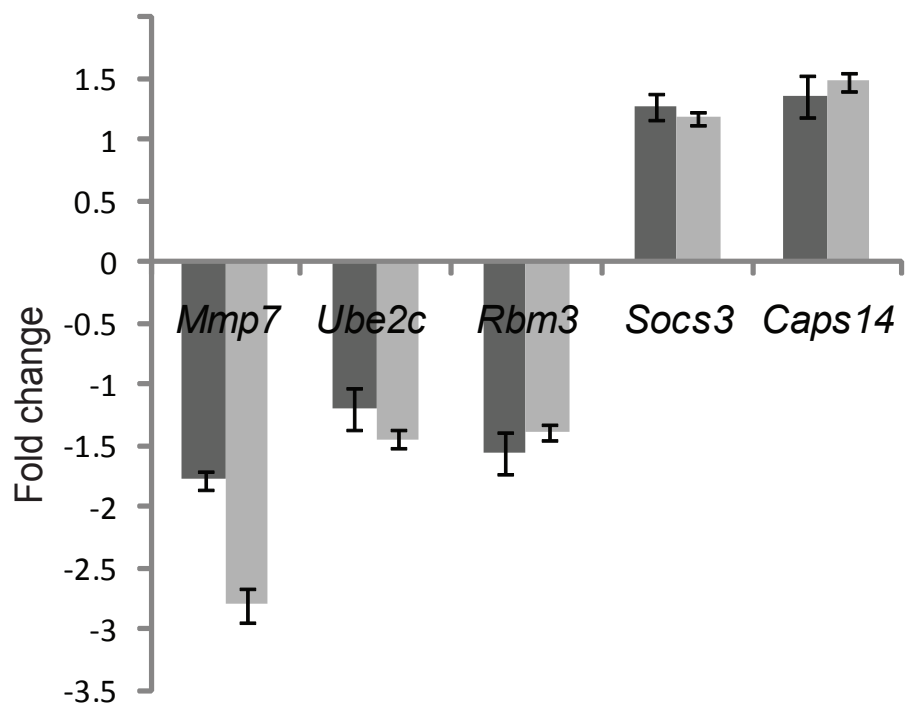

Gene name

Gene name

Figure 3 Real-time PCR analysis and Microarray Comparison. A: real-time PCR analysis and microarray comparison at the early stage of Infection. B: real-time PCR analysis and microarray comparison at the late stage of infection.

expression in microarray data and real-time PCR measurements at the early stage and the late stage of infection respectively. The gene expression changes measured by qRT-PCR were in agreement with microarray data.

The Pearson correction coefficient between the qRTPCR and microarray data was 0.836 . Therefore, the microarray provided a reliable comparison of gene expression in mouse colon mucous sample from salmonella SL1344 and SB1117 infection at 8 hours and 4 days.
Gene Ontology (GO) terms enrichment analysis for genes differentially expressed between the SL1344 and SB1117 infection groups

The analysis of enriched GO terms could aid in interpreting the dominant functions controlled by differentially expressed genes. To further address the potential contribution of AvrA to the S. typhimurium SP-I TTSSmediated stimulation of transcriptional response in mouse intestine, we evaluated the biological processes for these differentially expressed genes, using the $\mathrm{GO}$ term enrichment on-line analysis tool, GOEAST (Gene 
Table 1 List of biologic process for the up-expressed genes in SL1344 infection group relative to that of SB1117 infection group at $8 \mathrm{hr}$

\begin{tabular}{llc}
\hline GO ID & Term & No. of genes \\
\hline GO:0007154 & cell communication & 71 \\
GO:0007165 & signal transduction & 64 \\
\hline
\end{tabular}

Ontology Enrichment Analysis Software Toolkit) [21]. Table 1, 2, 3, 4 lists important Gene Ontologies with P-values less than 0.05 .

In 347 up-regulated genes in the SL1344 infection group relative to SB1117 infection group at 8 hours (Table 1), 230 transcripts were assigned specific GO terms. GOEAST analysis showed that most of these genes participated in cell communication (71 genes) and signal transduction (64 genes).

Shown in Table 2, 227 genes were down-regulated in the SL1344 infected group relative to SB1117 infection group at 8 hours. We found that 174 transcripts were assigned specific GO terms. Of these transcripts, $76.6 \%$ were annotated as being involved in biological processes, and a significant number of transcripts were assigned known functions in organelle organization (20 genes), cell cycle (14 genes), chromosome organization (10 genes), chromatin assembly and disassembly (9 genes), nucleosome organization (9 genes), protein-DNA complex assembly (9 genes), DNA packaging (9 genes), and cellular macromolecular complex assembly (9 genes). Annotation showed that many of the genes belong to the centromere protein and the histone family protein. This result indicates that most of biological processes down-regulated by AvrA relate to nuclear function.

In order to confirm the analysis results, we compared the cellular component of ontology for the two groups using the Multi-GOEAST analysis tool. As shown in Figure 4 all of the down-regulated GO terms are associated with the nucleus (green box), whereas up-regulated processes were associated with membrane and

Table 2 List of biologic process for the down-expressed genes in SL1344 infection group relative to that of SB1117 infection group at $8 \mathrm{hr}$

\begin{tabular}{llc}
\hline GO ID & Term & No. of genes \\
\hline GO:0006996 & organelle organization & 20 \\
GO:0007049 & cell cycle & 14 \\
GO:0051276 & chromosome organization & 10 \\
GO:0006334 & nucleosome assembly & 9 \\
GO:0031497 & chromatin assembly and disassembly & 9 \\
GO:0034728 & nucleosome organization & 9 \\
GO:0065004 & protein-DNA complex assembly & 9 \\
GO:0006323 & DNA packaging & 9 \\
GO:0034622 & cellular macromolecular complex assembly & 9
\end{tabular}

Table 3 List of biologic process for the up-expressed genes in SL1344 infection group relative to that of SB1117 infection group at 4 day $s$

\begin{tabular}{llc}
\hline GO ID & Term & $\begin{array}{c}\text { No. of } \\
\text { genes }\end{array}$ \\
\hline GO:0065007 & biological regulation & 70 \\
GO:0050794 & regulation of cellular process & 66 \\
GO:0032501 & multicellular organismal process & 47 \\
GO:0007165 & signal transduction & 45 \\
GO:0007154 & cell communication & 45 \\
GO:0007166 & cell surface receptor linked signal & 38 \\
& transduction & 14 \\
GO:0042221 & response to chemical stimulus & 10 \\
GO:0006915 & apoptosis & 10 \\
GO:0008219 & cell death & \\
\hline
\end{tabular}

cytoplasm (red box). We observed a significant GO annotation of condensed chromosome/nucleosome related activity (red arrow in Figure 4). Therefore, we speculate that chromosome/nucleosome process activities are strongly affected by AvrA at 8 hours post infection by SL1344.

In Table 3, 268 genes were up-regulated in the SL1344 vs SB1117 infection groups at 4 days. Among them, 134 transcripts were assigned specific GO terms. A significant number of transcripts were assigned known functions in biological regulation (70 genes), regulation of cellular process (67 genes), multicellular organismal process (47 genes), signal transduction (45 genes) and apoptosis (10 genes). An interesting result was that a total of 25 differentially expressed olfactory receptor family members participated in all of the biological processes except for apoptosis (Table 3).

In the SL1344 vs SB1117 infection group at 4 days, 337 genes were down-regulated genes (Table 4). Of these gene, 201 transcripts were assigned specific GO terms, and a significant number of transcripts were assigned known functions in system process regulation (39 genes), neurological system processes (37 genes), and $G$ protein-coupled receptor protein signaling

Table 4 List of biologic process for the down-expressed genes in SL1344 infection group relative to that of SB1117 infection group at 4 days

\begin{tabular}{llc}
\hline GO ID & Term & $\begin{array}{c}\text { No. of } \\
\text { genes }\end{array}$ \\
\hline GO:0003008 & system process & 39 \\
GO:0050877 & neurological system process & 37 \\
GO:0007186 & G-protein coupled receptor protein signaling & 35 \\
& pathway & \\
GO:0007608 & sensory perception of smell & 27 \\
GO:0007606 & sensory perception of chemical stimulus & 27 \\
GO:0007268 & synaptic transmission & 7
\end{tabular}




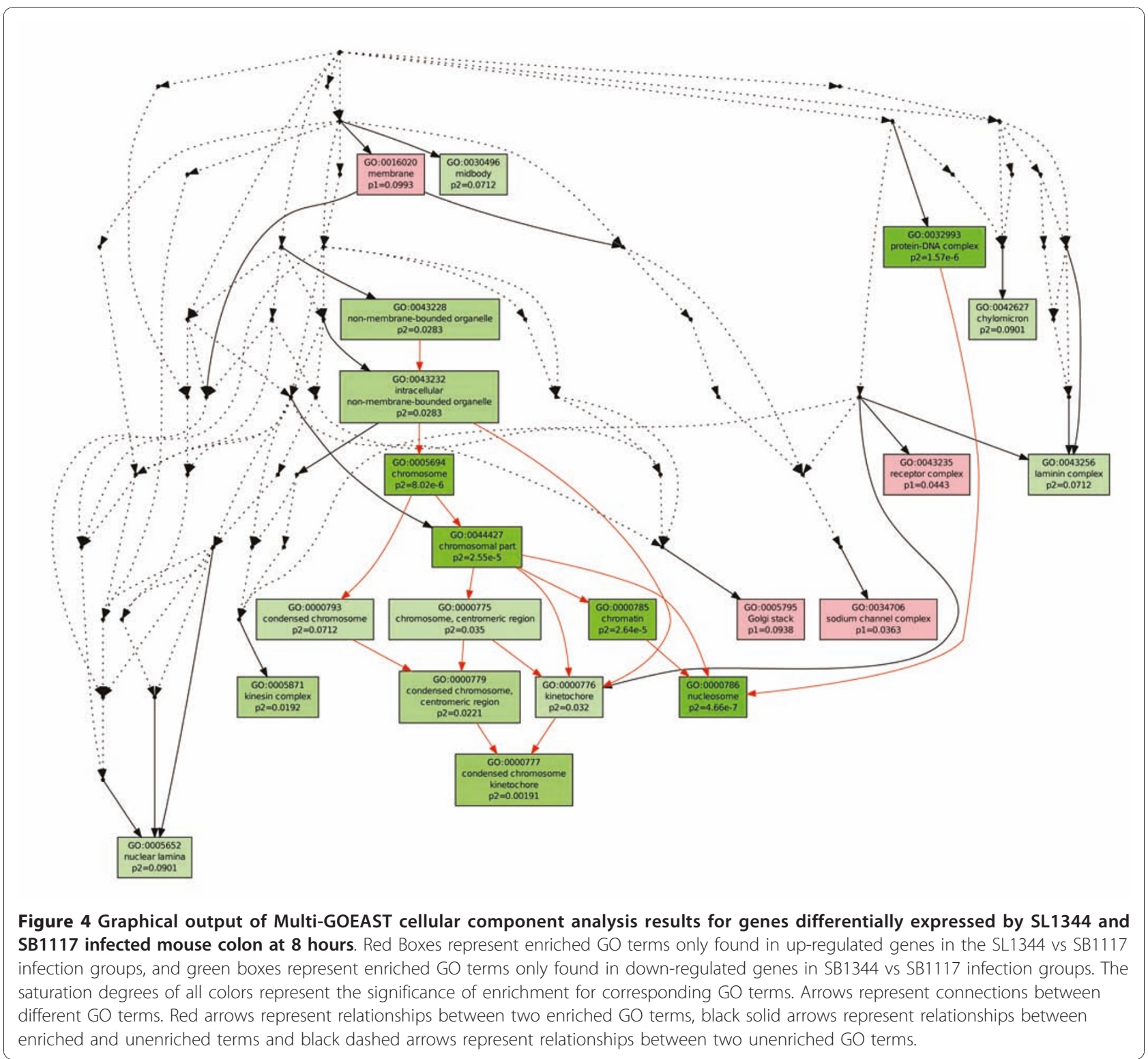

pathway (35 genes). These biological processes may underlie the physiological deficits of bacterial infection by inducing a decline in gene transcription.

The ontology of the cellular component for downregulated and up-regulated genes showed that most of molecular activity occurred in the cell membrane at 4 days post infection (data not shown).

\section{AvrA targeted specific pathway and network analysis}

An over-representation of a specific biological process does not indicate whether the process in question is being stimulated or repressed overall. We used IPA software to further investigate over- or under-represented functional activities of AvrA, specifically within the upregulated and down-regulated genes, at the stage of infection at 8 hours and 4 days. We focused on the ingenuity canonical pathways and addressed the differentially up-regulated genes between the SL1344 vs SB1117 infection groups at 8 hours and 4 days post infection (Table 5 and Table 6).

At 8 hours post Salmonella infection, shown in Table 5 up-expression of the Ras homolog gene family, RhoB, RhoC, RhoD and Rhou, targeted a total of 7 pathways: cholecystokinin/gastrin-mediated signaling; CXCR4 signaling; High-mobility group box 1(HMGB1) signaling; ILK signaling; integrin signaling; phospholipase $C$ signaling; production of Nitric Oxide, and reactive oxygen species in macrophages, and regulation of actin-based motility by Rho. We found that these pathways are associated with the following functions: cellular assembly 
Table 5 Target pathway of up-regulated Genes in SL1344 vs SB1117 infection groups at 8 hours

\begin{tabular}{|c|c|c|}
\hline Ingenuity Canonical Pathways & $\begin{array}{l}\text { Up- } \\
\text { regulated }\end{array}$ & Molecules \\
\hline Cholecystokinin/Gastrin mediated Signaling & $8 / 104(8 \%)$ & FOS, RHOV, JUN, RHOB, RHOD, IL1RN, RHOC, IL1F8 \\
\hline MIF Regulation of Innate Immunity & $3 / 46(7 \%)$ & FOS, LY96, JUN \\
\hline Complement System & $2 / 36(6 \%)$ & $\mathrm{C} 3, \mathrm{C} 1 \mathrm{~S}$ \\
\hline FAK Signaling & $6 / 98(6 \%)$ & CAPN5, ARHGAP26, CAPN9, CAPN2, ITGA3, ACTC1 \\
\hline HMGB1 Signaling & $6 / 98(6 \%)$ & FOS, RHOV, JUN, RHOB, RHOD, RHOC \\
\hline IL-10 Signaling & $4 / 70(6 \%)$ & FOS, JUN, IL1RN, IL1F8 \\
\hline \multirow[t]{2}{*}{ Integrin } & $\begin{array}{c}111 / 200 \\
(6 \%)\end{array}$ & $\begin{array}{l}\text { CAPN5, RHOV, ARHGAP26, RHOB, RHOD, ITGA11, RHOC, CAPN9, } \\
\text { CAPN2, ITGA3, ACTC1 }\end{array}$ \\
\hline & $7 / 112(6 \%)$ & PLCZ1, RHOV, RHOB, RHOD, RHOC, PLCL2, CASP14 \\
\hline Toll-like Receptor Signaling & $3 / 54(6 \%)$ & FOS, LY96, JUN \\
\hline B Cell A ctivating Factor Signaling & $2 / 44(5 \%)$ & FOS, JUN \\
\hline Coagulation System & $2 / 37(5 \%)$ & FGA, F3 \\
\hline CXCR4 Signaling & 8/168 (5\%) & FOS, RHOV, JUN, RHOB, RHOD, RHOC, EGR1, GNG5 \\
\hline IL-2 Signaling & $3 / 58(5 \%)$ & FOS, JUN, SYK \\
\hline ILK Signaling & 10/187(5\%) & MUC1, FOS, RHOV, JUN, RHOB, RHOD, RHOC, PPM1J, ACTC1, IRS3 \\
\hline Phototransduction Pathway & $3 / 65(5 \%)$ & OPN3, GRK1, PDE6H \\
\hline $\begin{array}{l}\text { Production of Nitric Oxide and reactive Oxygen Species in } \\
\text { Macrophages }\end{array}$ & 10/185 (5\%) & $\begin{array}{l}\text { FOS, RHOV, JUN, RHOB, PPP1R14 D, RHOD, RHOC, PPM1J, HOXA10, } \\
\text { SPI1 }\end{array}$ \\
\hline Regulation of Actin based & $5 / 93(5 \%)$ & $\mathrm{RHOV}, \mathrm{RHOB}, \mathrm{RHOD}$, \\
\hline Motility by Rho & & $\mathrm{RHOC}, \mathrm{ACTC} 1$ \\
\hline $\begin{array}{l}\text { Role of Cytokines in Mediating Communication between } \\
\text { Immune Cells }\end{array}$ & $3 / 57(5 \%)$ & IL1RN, IFNA5, IL1F8 \\
\hline \multirow{2}{*}{$\begin{array}{l}\text { Role of Pattern Recognition Receptors in Recognition of Bacteria } \\
\text { and Viruses }\end{array}$} & $4 / 86(5 \%)$ & IRF4, C3, SYK, IFNA5 \\
\hline & $4 / 114(4 \%)$ & PLCZ1, FOS, JUN, PLCL2 \\
\hline
\end{tabular}

Table 6 Target pathway of up-regulated genes in SL1344 vs SB1117 infection groups at 4 days

\begin{tabular}{lcl}
\hline Ingenuity Canonical Pathways & Up-regulated & Molecules \\
\hline Role of Cytokines in Mediating Communication between Immune Cells & $3 / 57(5 \%)$ & IFNG, IFNA7, IL3 HS6ST1, CYP3A4, 2810007J24RIK, \\
LPS/IL-1 Mediated Inhibi tion of RXR f unction & $5 / 215(2 \%)$ & IL4I1, ABCC4 \\
Interferon Signaling & $2 / 30(7 \%)$ & IFNG, IRF1 \\
Retinoic acid Mediated Apoptosis Signaling & $2 / 44(5 \%)$ & CFLAR, IRF1 \\
IL-12 Signaling and Pro duction in m acrophages & $3 / 134(2 \%)$ & IFNG, IF NA7, IRF1 \\
Ga12/13 Signaling & $3 / 126(2 \%)$ & BTK, F2RL2, MEF2D \\
Calcium -induced T Lymphocyte Apoptosis & $2 / 65(3 \%)$ & MEF2 D, ORAI1 \\
Prolactin Signaling & $2 / 75(3 \%)$ & SOCS3, IRF1 \\
VDR/RXR Activation & $2 / 80(3 \%)$ & IFNG, RUNX2 \\
Acute Phase Response Signaling & $3 / 178(2 \%)$ & SOCS3, TF, IL6R \\
Role of NFAT in Regulation of the Immune response & $3 / 195(2 \%)$ & BTK, MEF2 D, ORAI1 \\
Communication between Innate and adaptive Immune Cells & $2 / 90(2 \%)$ & IFNG, IL3 \\
FC Epsilon RI Signaling & $2 / 103(2 \%)$ & BTK, IL3 \\
Natural Killer Cell Signaling & $2 / 112(2 \%)$ & KLRK1, HCST \\
IL-22 Signaling & $1 / 28(4 \%)$ & SOCS3 \\
IL-15 Production & $1 / 31(3 \%)$ & IRF1 \\
p70S6K Signaling & $2 / 131(2 \%)$ & BTK, F2RL2 \\
IL-9 Signaling & $1 / 37(3 \%)$ & SOCS3 \\
JAK/Stat Signaling & $1 / 64(2 \%)$ & SOCS3 \\
\hline
\end{tabular}


and organization, cell to cell signaling and interaction, and infectious diseases.

Furthermore, we found that the up-regulated genes Fas and Jun, as transcription regulators, co-targeted many of pathways which are implicated as regulators of the stress response (production of Nitric Oxide and Reactive Oxygen Species in Macrophages pathway, IL-2 Signaling pathway, Toll-like Receptor Signaling, and CXCR4 Signaling pathway), inflammation (HMG1 pathway), proliferation (Cholecystokinin/Gastrin-mediated Signaling) and cell apoptosis (14-3-3 mediated signaling B Cell Activating Factor Signaling).

To clarify AvrA function in interactions between upregulated genes, we examined gene networks using IPA. As shown in Figure 5 this network presented IL1RN, NF- $\kappa \mathrm{B}$, and IL1 in central positions and corrected the following functions: Cellular assembly and organization, infectious disease, and tissue morphology. Based on the Ingenuity Pathway Knowledge base, around the NF- $\kappa \mathrm{B}$ central position, IL1F8, IFNA and IL1RA decrease NF$\kappa \mathrm{B}$ activation, whereas LY96, TNFRSF12A, SAA2, and Fibrinogen increase NF- $\kappa \mathrm{B}$ activation. This result showed that AvrA is involved in regulation of NF- $\kappa \mathrm{B}$ activation. However, AvrA's role in modulating the NF$\kappa \mathrm{B}$ activity may depend on a complex regulation network.

As shown in Figure 6 the network also showed the relevance of the Ras homolog, EGR1 group, Fas group and Jun group. In mouse M1 cell lines, EGR1 protein increases expression of mouse Junb mRNA [30]. The Salmonella Typhimurium type III Secretion effectors, SopE, SopE2 and SopB, stimulate Rho-family GTPase signaling [31,32] and innate immune responses [33,34]. Our study demonstrate that AvrA stabilizes the tight

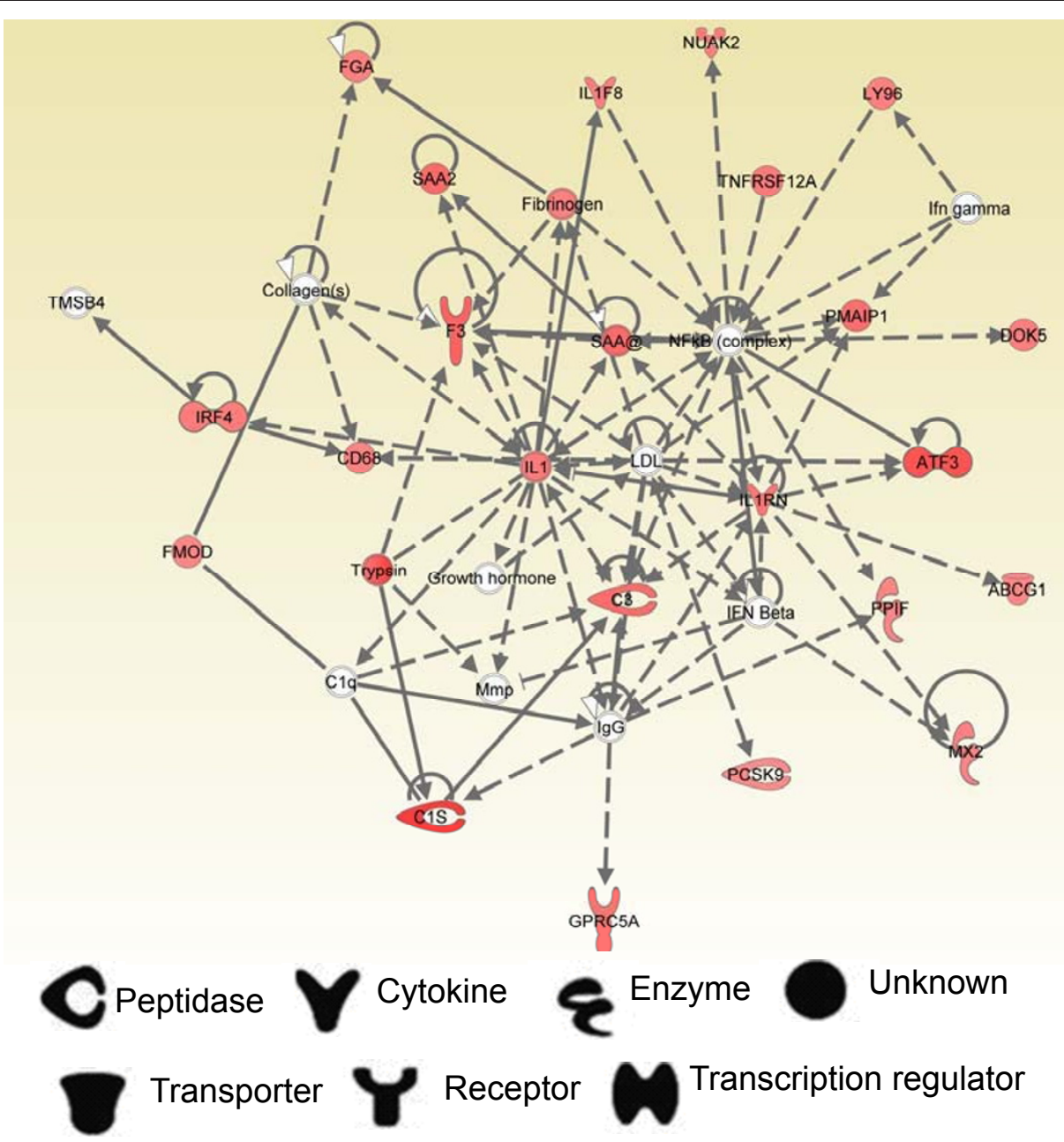

Figure 5 Ingenuity pathway Analysis network 1 depicting relationships among up-regulated genes in SB300 infection group relative to that of SB1117 infection group at $\mathbf{8}$ hours. Intensity of the red color indicates the degree of up-regulation. Nodes are displayed using various shapes that represent the functional class of the gene product. Edges are displayed with various labels that describe the nature of relationship between the nodes: _ represents direct relationship; ___ represents indirect relationship; $\rightarrow$ represents acts on. 


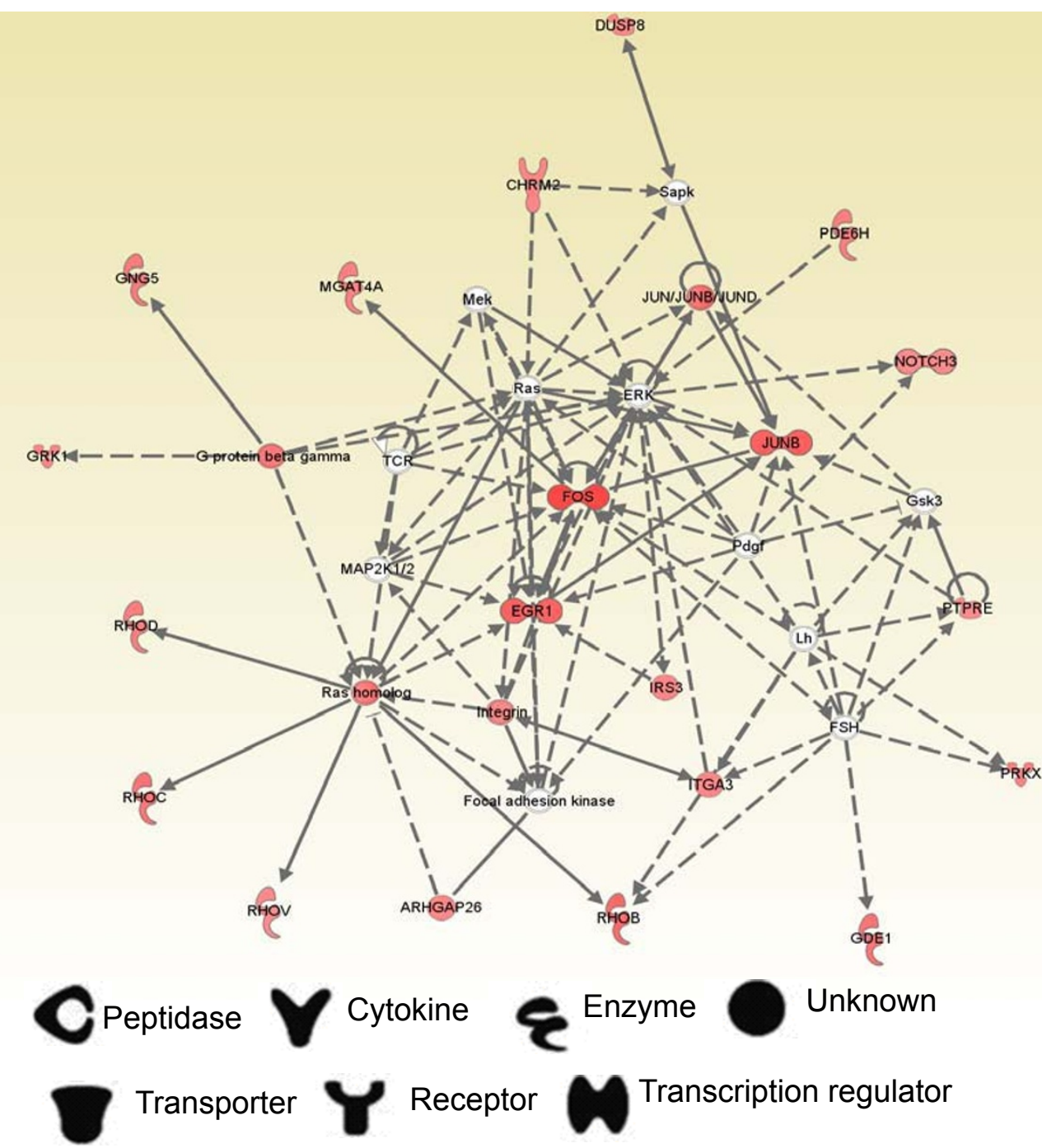

Figure 6 Ingenuity Pathway Analysis Network 2 depicting relationship among up-regulation Genes in SL1344 vs SB1117 infection groups at $\mathbf{8}$ hours. Intensity of the red color indicates the degree of up-regulation. Nodes are displayed using various shapes that represent the functional class of the gene product. Edges are displayed with various labels that describe the nature of relationship between the nodes: represents direct relationship, __ - represents indirect relationship $\rightarrow$ represents acts on.

junction structure and protein expression in vitro and in vivo [35]. Studies on AvrA demonstrated that AvrA reverses the activation of specific signaling pathways induced by effectors delivered by $S$. Typhimurium via the same TTSS [9]. Hence, the AvrA may have opposite effects on Rho-family GTPase, whereas the other Salmonella effectors stimulate Rho-family GTPase signaling.

Down-expressed genes in SL1344 vs SB1117 infection groups at 8 hours targeted mainly nuclear receptor signaling related pathway, such as PXR/RXR Activation, FXR/RXR Activation, and LPS/IL-1 Mediated Inhibition of RXR Function (Additional file 4 Table S4). The three pathways were co-targeted by the protein product of three genes, Cyp2c8 (Cytochrome $\mathrm{P}_{450} 2 \mathrm{C} 8$ ), Aldha1 (Aldehyde dehydrogenase 1 family, member A1), and
Prkag2 (5'-AMP-activated protein kinase subunit gamma-2). We also observed decreased expression of the gene for Fancd2 in the SL1344 infection group relative to SB1117 infection group. This protein is monoubiquinated in response to DNA damage, resulting in its localization to nuclear foci with other proteins (BRCA1 and BRCA2) involved in homology-directed DNA repair [36-38]. In other words, the down-regulation of Fancd2 in the SL1344 infection group relative to the control group implies that AvrA protects from DNA damage at the early stage of SL1344 infection. We also found that Socs2, which encodes a member of suppressors of cytokine signaling [39], is down-regulated in the SL1344 vs the SB1117 infection group. The Socs2 protein interacts with the cytoplasmic domain of insulin-like growth 
factor 1 receptor (IGF1R), and thus regulating IGF1R mediated cell signaling [39].

In addition, as shown in Additional file 3 Table S3, Socs 2 also targeted JAK pathway signal transduction adaptor activity and participated in regulation of cell growth and anti-apoptosis. Because Socs2 is a negative regulator of cytokine signal transduction that inhibits the JAK/STAT pathway $[40,41]$, the increased levels of the genes in the SL1117 infection group relative to control and SL1344 infection group may help to explain AvrA's proliferation role in activating JAK/STAT pathway at the early stage of SL1344 infection.

At 4 days post Salmonella infection, 5 up-regulated expressed genes in SL1344 infection group, compared to SB1117 infection group, overlap with a series of canonical pathways (Table 6): Ifng, Irf1, Btk, Mef2 d, and Socs3. These pathways have been associated with the following functions: cellular movement, the hematological system, cell proliferation and the hematopoiesis. Interferongamma (IFNG) is a cytokine critical for innate and adaptive immunity against viral and intracellular bacterial infections and for tumor control $[42,43]$. This result indicated that at the later stage of Salmonella infection AvrA may be involved in regulation of aberrant IFNG expression, which is associated with a number of autoinflammatory and autoimmune diseases.

We observed that another suppressor of cytokine signaling, Socs3, is up-regulated in the SL1344 vs. SB1117 infection groups at 4 days postinfection. This result contrasts with the down-expressed status of Socs 2 at 8 hours. As shown in Table 6 the expression of Socs 3 through the JAK/STAT pathway negatively regulates cytokine signaling, e.g., signaling of rolactin, acute phase response, IL-9, and IL-22. We found that these pathways are related to cell death; cellular growth and proliferation; as well as gastrointestinal and inflammatory disease. This finding suggests a possible role for AvrA that affects the above functions and diseases through regulation of cytokine signaling.

Down-expressed genes in the SL1344 vs. the SB1117 infection groups at 4 days targeted mainly metabolic related pathways, such as aminophosphonate, histideine and cysteine metabolism (Additional file 5 Table S5). The protein product of Prmt5, which is the protein arginine methyltransferase 5 involved in protein modification, targets these three pathways. As shown in Table S5, Casq1, Chrna4, and Ryrs are related to calcium signaling, and they are down-regulated in SL1344 vs. the SB11117 infection groups, but showed almost unchanged expression in the SL1344 infection group relative to the control. This result implies that AvrA negatively regulates calcium signaling in the late stage of SL1344 infection.

\section{AvrA function analysis during the time course of SL1344}

We further used the canonical pathway analysis software package in IPA software to determine whether and to what extent a given pathway is affected by the bacteria effector AvrA. We found many pathways with different signaling responses during the early and late stage of SL1344 and SB1117 infection. Figure 7 lists the nine representative pathways yielded by this analysis.

The mTOR signaling, Myc-mediated cell apoptosis signaling, PDGF, VEGF, JAK-STAT, and LPS-stimulated MAPK signaling were most significant at the stage of SL1344 infection compared to SB1117 infection after 4 days (Figure 7). However, these pathways were less significant at the early stage of SL1344 and SB1117 infection (8 hours). Hence, this analysis confirmed the functional performance of AvrA in late stage of SL1344 infection. We also found that these above pathways were closely related to biological processes of cell apoptosis. These observations are consistent with the signaling transduction studied on AvrA in anti-apoptosis $[7,8]$. Therefore, AvrA plays an essential role in antiapoptosis by regulating multiple signaling pathways in vivo.

Unlike the above pathways, oxidative phosphorylation showed the most significant signaling at the early stage of SL1344 vs. SB1117 infection. Our results also showed that AvrA had no important function in regulating oxidative phosphorylation pathway at the late stage of infection (Figure 7 Oxidative phosphorylation).

NF- $\kappa \mathrm{B}$ signaling is a key player in inflammation $[44,45]$. We found that NF- $\kappa \mathrm{B}$ was less significant in SL1344 vs. SB1117 infection at early stage of infection, but at the late stage of SL1344 infection, NF- $\kappa$ B signaling showed higher significance than that of SB1117 infection (Figure 7). Post-transcriptional study demonstrated that AvrA inhibits the NF- $\kappa \mathrm{B}$ activity though stabilizing the inhibitor of NF- $\kappa \mathrm{B}, \mathrm{I} \kappa \mathrm{B} \alpha[6,8]$. Overall, this result implies that AvrA suppressed the NF- $\kappa \mathrm{B}$ activity at the early stage of SL1344 infection and has a different regulatory role at the late stage.

In contrast, the significance values of SAPK/JNK signaling were low at late stages of SB1117 infection, which suggest that SL1117 infection is not associated with the SAPK/JNK pathway at the late stage of Infection.

\section{AvrA regulation of the mTOR, NF- $\kappa$ B, JNK, and oxidative phosphorylation signaling pathways in vivo}

It is possible that the genes that underlie the biology of a pathway could be different from one observation to another, even if the significant values remain unchanged. To evaluate this possibility, we performed a crossanalysis comparison of the genes associated with a given 


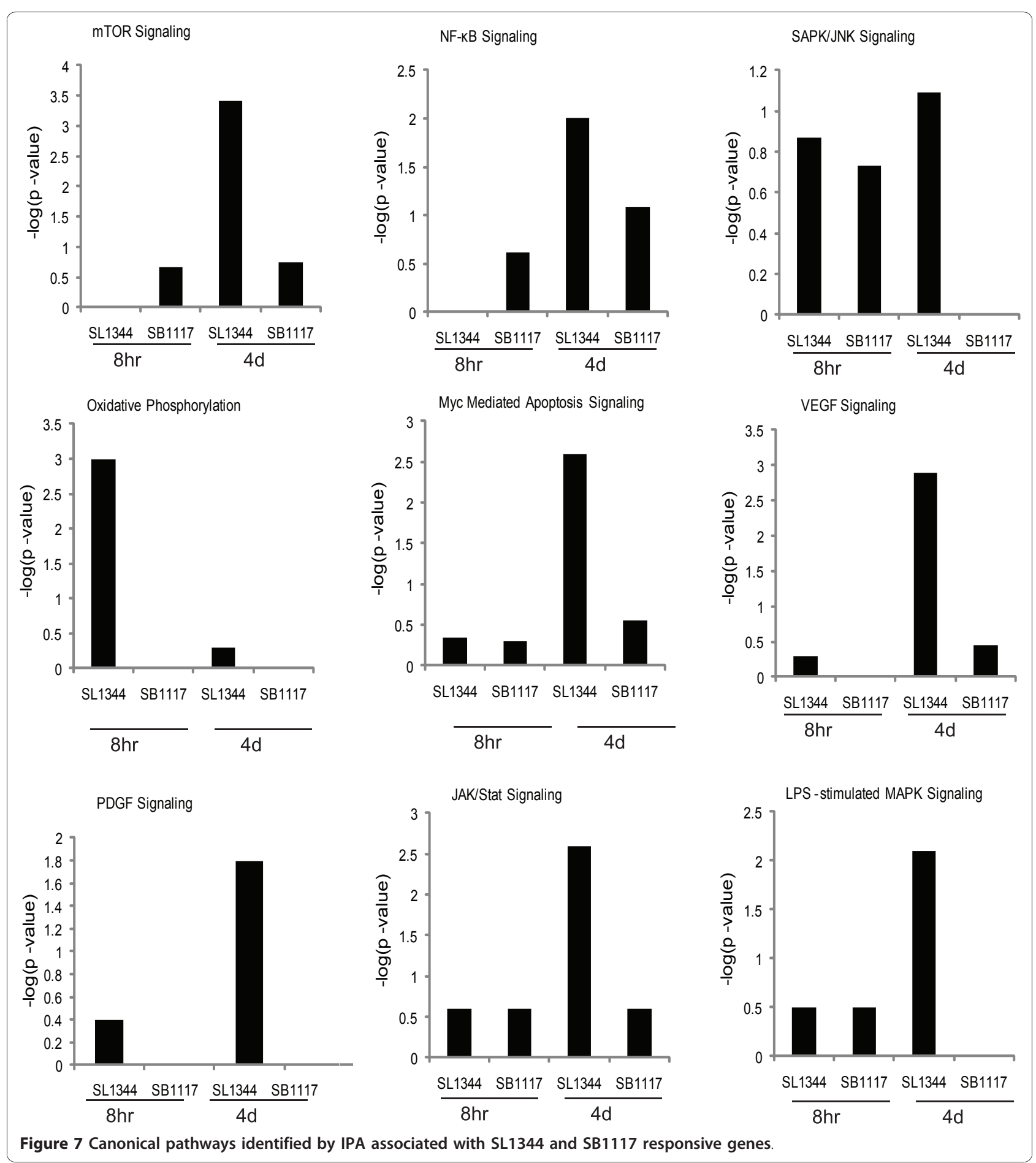

pathway during the early and late stages of SL1344 and SB1117 infection. To further analyze the AvrA regulation of the mTOR, NF- $\kappa \mathrm{B}$, JNK, and oxidative phosphorylation signaling pathways in vivo, we generated heat maps to investigate the associated genes in these pathways (Figure 8A-D).
As shown in Figure 8A, many genes of mTOR pathway play a role in cell proliferation, migration, apoptosis, differentiation, growth, and cell death. VEGFA, PIK3C2A, PIK3CD, PIK3C2G, and PRKCH showed upregulation in the SL1344 infection group at the late stage of infection, whereas in the SB1117 infection 


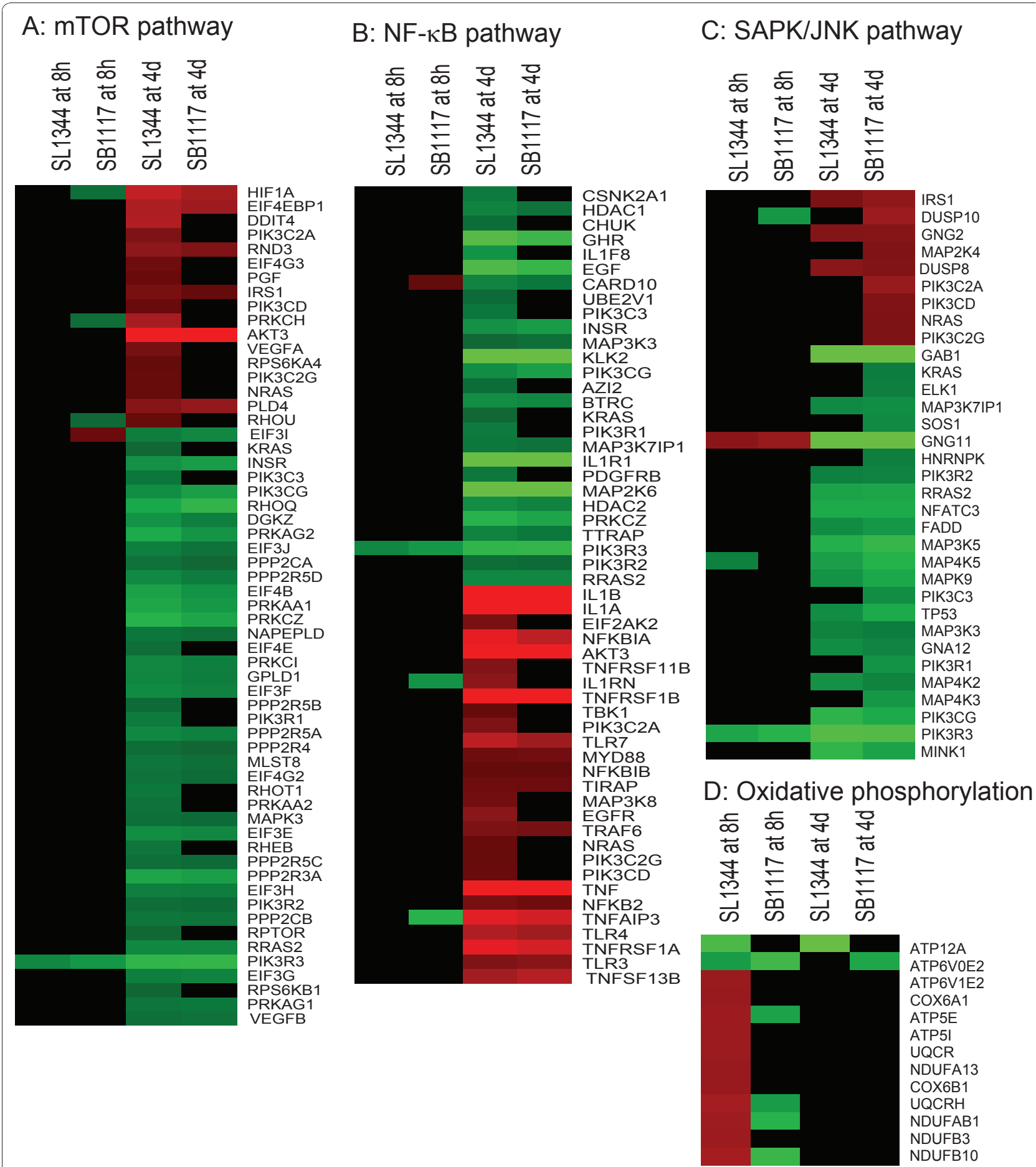

Figure 8 Heat maps of Salmonella-responses to gene expression changes involved in four signaling transduction pathways. A: mTOR signaling; B: NF- $\kappa$ B pathway C:SAPK/JNK signaling; D: Oxidative phosphorylation. Red denotes up-regulation; Green denotes down-regulated genes, black denotes unchanged or P-value $>0.05$ in three replicate experiments. 
group, the expression of these genes showed no significant change. These data indicated that AvrA is involved in the mTOR signaling pathway, thus playing a role in proliferation and apoptosis.

Figure 8B showed that Card10 was up-regulated at the early stage of SB1117 infection, but not at the early stage of SL1344 infection. The Card10 protein is a caspase recruitment domain/membrane-associated guanylate kinase family that interacts with BCL10 and activates NF- $\kappa \mathrm{B}$-inducing kinase activity [46]. Hence, the result showed that AvrA may inhibit NF- $\kappa$ B activation at the early stage of SL1344 infection relative to SB1117 infection. However, at the late stage of infection, many genes were differentially expressed between the SL1344 vs. SB1117 infection groups. These genes including down-regulated KRAS, PIK3R1, PDGFRB, $C H R, C H U K$ and CSNKIA1, as well as up-regulated genes TLR4, TLR3 and TLR7, EIF2AK2, TBk1, and $P I K 3 C 2 A$. Because the listed genes are involved in both negative and positive regulation for NF- $\kappa \mathrm{B}$ activation respectively, AvrA function for the NF- $\kappa \mathrm{B}$ pathway was more complex at the late stage of SL1344 infection.

We observed that Dusp10 is up-regulated at 8 hours post SB1117 infection, but no expression change was observed at 8 hours post SL1344 infection (Figure 8C). Because DUSP10 negatively regulates JNK and p38MAPK $[47,48]$, we reasoned that AvrA may stabilize DUSP10 expression to inhibit activation of JNK pathway at the early stage of SL1344 infection. However, more up-regulated and down-regulated genes that participate in response to the MAPKK signaling cascade are involved at the late stage of both SL1344 and SB1117 infection, there is no clear evidence that AvrA functions differently in the SAPK/JNK pathway at the late stage.

Figure 8D listed genes involved with oxidative phosphorylation at 8 hours post SL1344 infection, compared to the same time post SB11117 infection. These genes included ATP synthase family members (ATP5E, ATP5I, and ATP6V1), cytochrome $\mathrm{C}$ oxidase family members (Cox6A1 and Cox6B1), NADH dehydrogenase family members (NDUFA1, NDUFAB, NDUFB3, NDUDB1and NDUFS5), and Ubiquinol-cytochrome-c reductase family members (URCR and URCARH). The oxidative phosphorylation pathway covers a series of oxygen and redox reactions within mitochondria. AvrA may be involved in regulation of mitochondrial function at the early stage of infection.

\section{Comparison the role for AvrA in microarray analysis with previous study}

As shown in Table 7 several previous studies have reported that AvrA functions in these pathways, including JNK, NF- $\kappa \mathrm{B}, \mathrm{p} 53, \beta$-catenin, and tight-junction signaling. Similar to the previous results, our microarray analysis for AvrA role at the early stage of infection further reveal that AvrA can lead to gene expression changes of JNK and NF- $\kappa$ B pathway. Moreover, our study extended the understanding of AvrA in inhibiting the JNK and NF- $\kappa$ B pathways.

However, the microarray study has its limitations to identify the post-transcriptional and posttransductional behavior of the differentially expressed genes. This method may also have statistical error. We have demonstrated that Salmonella effector AvrA can activate $\beta$-catenin pathway through deubiquitination [8]. However, the activated pathway was not reveled in the current analysis. Hence, further studies combined genomic and proteomic are necessary to explore further details of AvrA function in interplaying with host cell.

\section{Conclusion}

In this study, we have used DNA microarrays to define the molecular regulators of intestinal signaling and host

Table 7 Summary of publications regarding the role for Salmonella AvrA in monolayers, drosophila, and mouse models.

\begin{tabular}{lll}
\hline Models & Pathways & References \\
\hline Monolayers & Tight-junction pathway & Liao et al., PLoS One. 2008 3(6):e236 \\
& Activated $\beta$-catenin pathway & Sun et al., Am J Physiol Gastrointest Liver Physiol. 2004 287(1):G220-7 \\
& Inhibited NF- $\kappa$ B pathway & Ye et al., Am J Pathol. 2007 171(3):882-92 \\
& Inhibited NF- $\kappa$ B pathway & Collier-Hyams et al., J Immunol. 2002 169(6):2846-50 \\
& Inhibited JNK pathway & Du and Galan, PLoS Pathog. 20095(9): e1000595 \\
& Inhibited JNK pathway & Jones et al, Cell Host Microbe. 2008 3(4):233-44 \\
Drosophila & Inhibited JNK, NF- $\kappa$ B pathway & Jones et al, Cell Host Microbe. 2008 3(4):233-44 \\
Mouse & Inhibited JNK, NF- $\kappa$ B pathway & Jones et al, Cell Host Microbe. 2008 3(4):233-44 \\
& Inhibited NF- $\kappa$ B pathway & Ye et al., Am J Pathol. 2007 171(3):882-92 \\
& Activated P53 pathway & Wu et al., Am J Physiol Gastrointest Liver Physiol. 2010 298(5):G784-94. \\
& Tight-junction pathway & Liao et al., PLoS One. 2008 Jun 4;3(6):e236 \\
& Activated $\beta$-catenin pathway $\beta$ & Ye et al., Am J Pathol. 2007 Sep;171(3):882-92 \\
& Activated Wnt/ $\beta$-catenin Pathway & Liu et al., FEBS Letter, 2010 584(5):911-916
\end{tabular}


defense expressed in adult $\mathrm{C} 57 \mathrm{Bl} / 6$ female mice during the early and late phases of infection with virulent SL1344 (AvrA+) or isogenic AvrA-Salmonella strains. We identified pathways, such as mTOR signaling, oxidative phosphorylation, NF- $\kappa \mathrm{B}$, VEGF, JAK-STAT, and MAPK signaling regulated by AvrA in vivo, which are associated with inflammation, anti-apoptosis and proliferation. At the early stage of Salmonella infection, down-regulated genes in the SL1344 vs SB1117 infection groups mainly targeted pathways related to nuclear signaling and up-regulated genes in the SL1344 vs SB1117 infection groups mainly targeted oxidative phosphorylation. At the late stage of Salmonella infection, AvrA inhibits Interferon-gamma responses. Both early and late phases of the host response exhibit remarkable specificity for the AvrA+ strain in intestine. These results provide new insights into the molecular cascade, which is mobilized to combat Salmonella-associated intestinal infection in vivo.

Our in vivo data indicated that the status of AvrA in Salmonella strains may alter the strains' ability to induce host responses, especially in the intestinal mucosa response. Our recent study on AvrA further demonstrates that AvrA enhances intestinal proliferation in vivo $[18,49]$. Although the exact function and mechanism of AvrA is not entirely clear, it is known that AvrA is a multifunctional protease that influences eukaryotic cell pathways that utilize ubiquitin and acetylation, thus inhibiting apoptosis and promoting intestinal proliferation $[7,8]$.

Our microarray data analysis indicated that NF- $\kappa \mathrm{B}$ is one of the top-10 signaling pathways targeted by AvrA in vivo. A recent study showed that AvrA inhibits the Salmonella-induced JNK pathway but showed a very weak inhibition of the NF- $\kappa \mathrm{B}$ signaling [9]. The different findings about the AvrA's regulation of the NF- $\kappa \mathrm{B}$ pathway may be due to the different experimental system used and different stage post infection. Because the NF$\kappa \mathrm{B}$ is centrally involved of inflammatory networking, other functions of AvrA may indirectly influence the NF- $\kappa$ B activity $[35,50]$.

AvrA status affects levels of expression of the other effector proteins in Salmonella ([51] and unpublished data). Stimulation of inflammation by bacterial effectors is crucial for Salmonella to grow in the intestine [52,53]. However, un-controlled inflammation is harmful to the host and eventually damages the niche involved Salmonella growth. AvrA plays a role opposite to that of the other known effectors by inhibiting the inflammatory responses in intestine. Hence, one could argue that AvrA's role in inhibiting inflammation allows the pathogen to survive well in the host, thus establishing a mutually beneficial relationship.
Our current study investigated gene expression at the mRNA level in response to AvrA. Posttranscriptional modification by AvrA cannot be identified by DNA array analysis. Study using Western blot and other protein assay methods will provide further insights into the AvrA's regulation of eukaryotic proteins in intestine.

Taken together, our findings show that AvrA specifically inhibits inflammatory responses and promotes proliferation in vivo. It is important to understand how AvrA works in vivo because of the Salmonella problems and the bioweapon threat of bacterial toxins. We believe that studies on the action of bacterial effectors will uncover new facets of bacterial-host interaction that may lead to the development of new therapeutic drugs or vaccines against important human pathogens.

\section{Additional material}

Additional file 1: Table S1. Primer sequence for qRT-PCR. Listing all primer sequences used in GRT-PCR (PDF file). PCR data were shown in Figure 3.

Additional file 2: Table S2. Differentially expressed genes between the SL1344 infection and the SB1117 infection at early stage. The list of differentially expressed genes between the SL1344 infection and the SB1117 infection at 8 hours post-infection ( $P \leq 0.05$ with fold change $\geq 1.2$ or $\leq-1.2$ ).

Additional file 3: Table S3. Differentially expressed genes between the SL1344 infection and the SB1117 infection at late stage. The list of differentially expressed genes between the SL1344 infection and the SB1117 infection at 4 days post-infection $(P \leq 0.05$ with fold change $\geq 1.2$ or $\leq-1.2)$.

Additional file 4: Table S4. Target pathway of down-regulated genes in SL1344vs SB1117 infection group at 8 hours. Listing target pathway of down-regulated genes in SL1344vs SB1117 infection group at 8 hours post-infection.

Additional file 5: Table S5. Target pathway of down-regulated genes in SL1344 vs SB1117 infection group at 4 days. Listing target pathway of down-regulated genes in SL1344vs SB1117 infection group at 4 day post-infection.

\section{Abbreviations}

CXCR4: CXC chemokine receptor 4, also known as fusin; EGF: Epidermal growth factor; Erk: extracellular signal-regulated kinases; GO: Gene ontology; GSK-3: glycogen synthase kinase 3; HMGB1: High-mobility group box 1; IBD: inflammatory bowel diseases; ICAM: intercellular adhesion molecule; IFNA: Interferon-alpha; IFNG: Interferon-gamma; IKBa: Inhibitor of NF-KB; IKK: IKB kinase; IPA: Ingenuity Pathways Analysis; IL1RA: IL-1 receptor antagonist; IGF1R: insulin-like growth factor 1 receptor; JAK-STAT:Janus kinases-Signal Transducers and Activators of Transcription protein JNK: JUN-NH ${ }_{2}$-terminal kinase; LPS: Lipopolysaccharides; MAPK: mitogen-activated protein kinase; MKK7: Mitogen-activated protein kinase kinase 7, also known as MAP2K7; MCP-1: monocyte chemoattractant protein 1; mTOR: mammalian target of rapamycin; NF-kB: Nuclear factor KB; PDGF: platelet-derived growth factors; PXR: pregnane $\times$ receptor, or NR1I2 (nuclear receptor subfamily 1, group I, member 2) RXR: Retinoid $\times$ receptor; SAKP: Stress-activated protein kinase; TLR: Toll-like receptor; TNF: Tumor necrosis factor; TNFRSF12A: Tumor necrosis factor receptor superfamily member 12A; TTSS: Type Three Secretion System; STRAF6: tumor necrosis factor receptor-associated factor-6; VEGF: vascular endothelial growth factor; YopJ: Yersinia outer protein J 


\section{Acknowledgements}

We thank Dr. Constance D. Baldwin at the University of Rochester for critical revising and editing of this manuscript, Xi Emma Li for her excellent technical support, Julia Militar for helpful editing, and Jody Bown for helpful suggestion on microarray software. This work was supported by the NIDDK KO1 DK075386 and the American Cancer Society RSG-09-075-01-MBC to Jun Sun.

\section{Author details}

'Department of Medicine, Gastroenterology \& Hepatology Division, University of Rochester, 601 Elmwood Avenue, Rochester, NY 14642, USA. ${ }^{2}$ Department of Biostatistics and Computational Biology, University of Rochester, 601 Elmwood Avenue, Rochester, NY 14642, USA. ${ }^{3}$ Department of Microbiology and Immunology, University of Rochester, 601 Elmwood Avenue, Rochester, NY 14642, USA. ${ }^{4}$ Wilmot Cancer Center, University of Rochester, 601 Elmwood Avenue, Rochester, NY 14642, USA.

\section{Authors' contributions}

$\mathrm{XL}$ : participated in experimental design, animal experiment, preparation of RNA sample, real-time PCR, western blot and immunofluorescence analysis, acquisition of data, analysis and interpretation of data, carried out bioinformatics analysis, and drafted table, figure and the manuscript. RL: participated in experimental design, analysis and interpretation of data, real-time PCR analysis, drafted tables and figures, and carried out animal experiments.

YX: participated in interpretation of data, performed statistical analysis, and edited the manuscript for important intellectual content.

SW: participated in experimental design, technical support, animal experiments, analysis and interpretation of data.

JS: participated in study concept and design, acquisition of data, analysis and interpretation of data, material support, writing and critical revision of the manuscript for critical intellectual content, obtained funding, and supervised study.

All authors read and approved the final manuscript.

Received: 3 February 2010 Accepted: 23 December 2010 Published: 23 December 2010

\section{References}

1. Coburn B, Li Y, Owen D, Vallance BA, Finlay BB: Salmonella enterica serovar typhimurium pathogenicity island 2 is necessary for complete virulence in a mouse model of infectious enterocolitis. Infection and immunity 2005, 73(6):3219-3227.

2. Coburn B, Sekirov I, Finlay BB: Type iii secretion systems and disease. Clinical microbiology reviews 2007, 20(4):535-549.

3. Hardt WD, Galan JE: A secreted salmonella protein with homology to an avirulence determinant of plant pathogenic bacteria. Proc natl acad sci USA 1997, 94(18):9887-9892.

4. Streckel W, Wolff AC, Prager R, Tietze E, Tschape H: Expression profiles of effector proteins sopb, sopd1, sope1, and avra differ with systemic, enteric, and epidemic strains of salmonella enterica. Mol nutr food res 2004, 48(7):496-503.

5. Orth K, Xu Z, Mudgett MB, Bao ZQ, Palmer LE, Bliska JB, Mangel WF, Staskawicz B, Dixon JE: Disruption of signaling by yersinia effector yopj, a ubiquitin-like protein protease. Science 2000, 290(5496):1594-1597.

6. Collier-Hyams LS, Zeng H, Sun J, Tomlinson AD, Bao ZQ, Chen H, Madara JL, Orth K, Neish AS: Cutting edge: salmonella avra effector inhibits the key proinflammatory, anti-apoptotic NF-kappaB pathway. J Immunol 2002, 169(6):2846-2850.

7. Jones RM, Wu H, Wentworth C, Luo L, Collier-Hyams L, Neish AS: Salmonella avra coordinates suppression of host immune and apoptotic defenses via jnk pathway blockade. Cell host microbe 2008, 3(4):233-244.

8. Ye Z, Petrof EO, Boone D, Claud EC, Sun J: Salmonella effector avra regulation of colonic epithelial cell inflammation by deubiquitination. Am J Pathol 2007, 171(3):882-892.

9. Du F, Galan JE: Selective inhibition of type iii secretion activated signaling by the salmonella effector avra. Plos Pathog 2009, 5(9):E1000595.

10. Chang J, Chen J, Zhou D: Delineation and characterization of the actin nucleation and effector translocation activities of salmonella sipc. $\mathrm{Mol}$ Microbiol 2005, 55(5):1379-1389.
11. Eckmann L, Smith JR, Housley MP, Dwinell MB, Kagnoff MF: Analysis by high density cdna arrays of altered gene expression in human intestinal epithelial cells in response to infection with the invasive enteric bacteria salmonella. The Journal of Biological Chemistry 2000, 275(19):14084-14094.

12. Wang Y, Couture OP, Qu L, Uthe JJ, Bearson SM, Kuhar D, Lunney JK, Nettleton D, Dekkers JC, Tuggle CK: Analysis of porcine transcriptional response to salmonella enterica serovar choleraesuis suggests novel targets of NFkappaB are activated in the mesenteric lymph node. BMC Genomics 2008, 9:437.

13. Chiang HI, Swaggerty CL, Kogut MH, Dowd SE, Li X, Pevzner IY, Zhou H: Gene expression profiling in chicken heterophils with salmonella enteritidis stimulation using a chicken $44 \mathrm{k}$ agilent microarray. BMC Genomics 2008, 9:526.

14. Rodenburg W, Bovee-Oudenhoven IM, Kramer E, Van der Meer R, Keijer J: Gene expression response of the rat small intestine following oral salmonella infection. Physiol Genomics 2007, 30(2):123-133.

15. Sun J, Hobert ME, Rao AS, Neish AS, Madara JL: Bacterial activation of beta-catenin signaling in human epithelia. Am J Physiol Gastrointest Liver Physiol 2004, 287(1):G220-227.

16. Mccormick BA, Colgan SP, Delp-Archer C, Miller SI, Madara JL: Salmonella typhimurium attachment to human intestinal epithelial monolayers: transcellular signalling to subepithelial neutrophils. J Cell Biol 1993, 123(4):895-907.

17. Duan Y, Liao AP, Kuppireddi S, Ye Z, Ciancio MJ, Sun J: Beta-catenin activity negatively regulates bacteria-induced inflammation. Lab Invest 2007, 87(6):613-624.

18. Lu R, Wu S, Liu X, Xia Y, Zhang YG, Sun J: Chronic effects of a salmonella type iii secretion effector protein avra in vivo. Plos One 2010, 5(5):E10505.

19. Jickling GC, Zhan X, Ander BP, Turner RJ, Stamova B, Xu H, Tian Y, Liu D, Davis RR, Lapchak PA, et al: Genome response to tissue plasminogen activator in experimental ischemic stroke. BMC Genomics 2010, 11:254

20. Strath J, Georgopoulos LJ, Kellam P, Blair GE: Identification of genes differentially expressed as result of adenovirus type 5- and adenovirus type 12-transformation. BMC Genomics 2009, 10:67.

21. Zheng $\mathrm{Q}$, Wang XJ: Goeast: a web-based software toolkit for gene ontology enrichment analysis. Nucleic Acids Res 2008, 36 Web Server: W358-363.

22. Li CJ, Li RW, Wang YH, Elsasser TH: Pathway analysis identifies perturbation of genetic networks induced by butyrate in a bovine kidney epithelial cell line. Funct Integr Genomics 2007, 7(3):193-205.

23. Lagoa CE, Bartels J, Baratt A, Tseng G, Clermont G, Fink MP, Billiar TR, Vodovotz $Y$ : The role of initial trauma in the host's response to injury and hemorrhage: insights from a correlation of mathematical simulations and hepatic transcriptomic analysis. Shock 2006, 26(6):592-600.

24. Calvano SE, Xiao W, Richards DR, Felciano RM, Baker HV, Cho RJ, Chen RO, Brownstein BH, Cobb JP, Tschoeke SK, et al: A network-based analysis of systemic inflammation in humans. Nature 2005, 437(7061):1032-1037.

25. Livak KJ, Schmittgen TD: Analysis of relative gene expression data using real-time quantitative pcr and the 2(-delta delta $c(t))$ method. Methods 2001, 25(4):402-408.

26. Wu S, Ye Z, Liu X, Zhao Y, Xia Y, Steiner A, Petrof EO, Claud EC, Sun J: Salmonella typhimurium infection increases p53 acetylation in intestinal epithelial cells. Am J Physiol Gastrointest Liver Physiol 2010, 298(5):G784-794.

27. Kerrinnes T, Zelas ZB, Streckel W, Faber F, Tietze E, Tschape H, Yaron S: Csra and csrb are required for the post-transcriptional control of the virulence-associated effector protein avra of salmonella enterica. Int $J$ Med Microbiol 2009, 299(5):333-341.

28. Raelson JV, Little RD, Ruether A, Fournier H, Paquin B, Van Eerdewegh $P$, Bradley WE, Croteau P, Nguyen-Huu Q, Segal J, et al: Genome-wide association study for crohn's disease in the quebec founder population identifies multiple validated disease loci. Proc Natl Acad Sci USA 2007, 104(37):14747-14752

29. Gradel KO, Nielsen HL, Schonheyder HC, Ejlertsen T, Kristensen B, Nielsen H: Increased short- and long-term risk of inflammatory bowel disease after salmonella or campylobacter gastroenteritis. Gastroenterology 2009, 137(2):495-501.

30. Krishnaraju K, Hoffman B, Liebermann DA: The zinc finger transcription factor egr-1 activates macrophage differentiation in $\mathrm{m} 1$ myeloblastic leukemia cells. Blood 1998, 92(6):1957-1966. 
31. Hardt WD, Chen LM, Schuebel KE, Bustelo XR, Galan JE: S. Typhimurium encodes an activator of rho gtpases that induces membrane ruffling and nuclear responses in host cells. Cell 1998, 93(5):815-826.

32. Boyle EC, Brown NF, Finlay BB: Salmonella enterica serovar typhimurium effectors sopb, sope, sope 2 and sipa disrupt tight junction structure and function. Cell Microbiol 2006, 8(12):1946-1957.

33. Bruno VM, Hannemann S, Lara-Tejero M, Flavell RA, Kleinstein SH, Galan JE: Salmonella typhimurium type iiisecretion effectors stimulate innate immune responses in cultured epithelial cells. Plos Pathog 2009, 5(8): E1000538

34. Hapfelmeier S, Ehrbar K, Stecher B, Barthel M, Kremer M, Hardt WD: Role of the salmonella pathogenicity island 1 effector proteins sipa, sopb, sope, and sope 2 in salmonella enterica subspecies 1 serovar typhimurium colitis in streptomycin-pretreated mice. Infection and Immunity 2004, 72(2):795-809.

35. Liao AP, Petrof EO, Kuppireddi S, Zhao Y, Xia Y, Claud EC, Sun J: Salmonella type iii effector avra stabilizes cell tight junctions to inhibit inflammation in intestinal epithelial cells. Plos One 2008, 3(6):E2369.

36. Wang $X, D^{\prime}$ Andrea $A D$ : The interplay of fanconi anemia proteins in the dna damage response. Dna Repair (Amst) 2004, 3(8-9):1063-1069.

37. Meetei $A R$, Yan Z, Wang W: Fancl replaces brca1 as the likely ubiquitin ligase responsible for fancd2 monoubiquitination. Cell Cycle 2004, 3(2):179-181.

38. Fei $P$, Yin J, Wang $W$ : New advances in the dna damage response network of fanconi anemia and brca proteins. faap95 replaces brca2 as the true fancb protein. Cell Cycle 2005, 4(1):80-86.

39. Dey BR, Spence SL, Nissley P, Furlanetto RW: Interaction of human suppressor of cytokine signaling (socs)-2 with the insulin-like growth factor-i receptor. The Journal of Biological Chemistry 1998, 273(37):24095-24101

40. Hilton DJ, Richardson RT, Alexander WS, Viney EM, Willson TA, Sprigg NS, Starr R, Nicholson SE, Metcalf D, Nicola NA: Twenty proteins containing a c-terminal socs box form five structural classes. Proc Natl Acad Sci USA 1998, 95(1):114-119.

41. Chen XP, Losman JA, Rothman P: Socs proteins, regulators of intracellular signaling. Immunity 2000, 13(3):287-290

42. Schoenborn JR, Wilson CB: Regulation of interferon-gamma during innate and adaptive immune responses. Adv Immunol 2007, 96:41-101.

43. Schoenborn JR, Dorschner MO, Sekimata M, Santer DM, Shnyreva M Fitzpatrick DR, Stamatoyannopoulos JA, Wilson CB: Comprehensive epigenetic profiling identifies multiple distal regulatory elements directing transcription of the gene encoding interferon-gamma. Nat Immunol 2007, 8(7):732-742.

44. Greten FR, Eckmann L, Greten TF, Park JM, Li ZW, Egan LJ, Kagnoff MF, Karin M: Ikkbeta links inflammation and tumorigenesis in a mouse model of colitis-associated cancer. Cell 2004, 118(3):285-296.

45. Greten FR, Arkan MC, Bollrath J, Hsu LC, Goode J, Miething C, Goktuna SI, Neuenhahn M, Fierer J, Paxian S, et al: Nfkappab is a negative regulator of il-1beta secretion as revealed by genetic and pharmacological inhibition of ikkbeta. Cell 2007, 130(5):918-931.

46. Wang L, Guo Y, Huang WJ, Ke X, Poyet JL, Manji GA, Merriam S, Glucksmann MA, Distefano PS, Alnemri ES, et al: Card10 is a novel caspase recruitment domain/membrane-associated guanylate kinase family member that interacts with bcl10 and activates NF-kappaB. The Journal of Biological Chemistry 2001, 276(24):21405-21409.

47. Teng $\mathrm{CH}$, Huang WN, Meng TC: Several dual specificity phosphatases coordinate to control the magnitude and duration of jnk activation in signaling response to oxidative stress. The Journal of Biological Chemistry 2007, 282(39):28395-28407.

48. Lang R, Hammer M, Mages J: Dusp meet immunology: dual specificity mapk phosphatases in control of the inflammatory response. J Immunol 2006, 177(11):7497-7504.

49. Liu X, Lu R, Wu S, Sun J: Salmonella regulation of intestinal stem cells through the wnt/beta-catenin pathway. Febs Lett 2010, 584(5):911-916.

50. Sun J, Hobert ME, Duan Y, Rao AS, He TC, Chang EB, Madara JL: Crosstalk between NF-kappaB and beta-catenin pathways in bacterial-colonized intestinal epithelial cells. Am J Physiol Gastrointest Liver Physiol 2005, 289(1):G129-137

51. Ma J, Zhang YG, Xia Y, Sun J: The inflammatory cytokine tumor necrosis factor modulates the expression of salmonella typhimurium effector proteins. J Inflamm (Lond) 2010, 7:42.
52. Stecher B, Robbiani R, Walker AW, Westendorf AM, Barthel M, Kremer M Chaffron S, Macpherson AJ, Buer J, Parkhill J, et al: Salmonella enterica serovar typhimurium exploits inflammation to compete with the intestinal microbiota. Plos Biol 2007, 5(10):2177-2189.

53. Liu X, Lu R, Xia Y, Sun J: Global analysis of the eukaryotic pathways and networks regulated by Salmonella Typhimurium in mouse intestinal infection in vivo. BMC Genomics 2010, 11(1):722.

doi:10.1186/1471-2180-10-326

Cite this article as: Liu et al:: Eukaryotic signaling pathways targeted by Salmonella effector protein AvrA in intestinal infection in vivo. BMC Microbiology 2010 10:326.

\section{Submit your next manuscript to BioMed Central and take full advantage of:}

- Convenient online submission

- Thorough peer review

- No space constraints or color figure charges

- Immediate publication on acceptance

- Inclusion in PubMed, CAS, Scopus and Google Scholar

- Research which is freely available for redistribution

Submit your manuscript at www.biomedcentral.com/submit
Biomed Central 